\title{
ANALYSIS OF JOB STRESS IN WORKERS EMPLOYED BY THREE PUBLIC ORGANIZATIONS IN SERBIA
}

\author{
ALEKSANDAR ALEKSIĆ ${ }^{1}$, MARIJANA TRKULJA ${ }^{2}$, \\ BOJANA CIKOTA-ALEKSIĆ ${ }^{3}$, and DRAGAN ALEKSIĆ ${ }^{1}$ \\ ${ }^{1}$ Institute of Occupational Health, Belgrade, Serbia \\ Military Medical Academy \\ ${ }^{2}$ Institute of Occupational Health, Belgrade, Serbia \\ "Dr Dragomir Karajović" \\ ${ }^{3}$ Institute of Medical Research, Belgrade, Serbia \\ Military Medical Academy
}

\begin{abstract}
Objectives: The present study analyzes job stress in terms of education, age and the presence of cardiovascular and endocrine/metabolic diseases. Material and Methods: A total of 411 workers employed by three public organizations completed the Job Content Questionnaire to classify their jobs based on the job strain model. Data about health condition, education and habits was obtained by the use of medical examinations and an interview. Results: The analysis of the completed Job Content Questionnaires indicates that workers with high education have significantly higher decision latitude (DL) than low-educated workers (one-way ANOVA, $\mathrm{p}<0.0001$ ). DL was also different between age groups (one-way ANOVA, $\mathrm{p}<0.0001)$ - the highest DL values were observed in the oldest group, while the lowest DL mean was found in the youngest group. Psychological job demands (PJD) and social support (SS) were not significantly different between educational and age groups. The frequency of job stress categories was significantly different between low and highly-educated workers $\left(\chi^{2}\right.$ test, $\left.\mathrm{df}=3, \mathrm{p}<0.0001\right)$ and also between different age groups $\left(\chi^{2}\right.$ test, $\left.\mathrm{df}=6, \mathrm{p}<0.0001\right)$. The majority of highly-educated men were exposed to "active" jobs (high PJD and high DL). Most frequently, men older than 45 years experienced jobs with high DL ("active" and "low strain"), men aged 35 to 45 years were exposed to jobs with high PJD ("high strain" and "active") while the majority of men younger than 35 years were exposed to jobs with low DL ("high strain" and "passive"). No association between cardiovascular and endocrine/metabolic disorders and different job stress categories was observed. Conclusion: "High strain" and "passive" jobs were most frequently identified among low-educated and young men. Despite the absence of association between job stress and cardiovascular and endocrine/metabolic diseases, we recommend prevention of work stress, particularly in the case of low-educated workers and workers younger than 45 years exposed to unfavorable job stress categories.
\end{abstract}

Key words:

Job Content Questionnaire, Job strain, Health-related problems

Received: March 12, 2012. Accepted: March 13, 2013.

Corresponding author: A. Aleksić, Military Medical Academy, Institute of Occupational Health, 17 Crnotravska,11000 Belgrade, Serbia (e-mail: aleksic.aleksandar7@gmail.com). 


\section{INTRODUCTION}

For several years now, chronic stress has been assessed in a wide range of applied and fundamental investigations. The majority of studies have analyzed the impact of chronic stress on health-related problems. As a result, it has been shown that chronic as well as acute stress may influence both innate and adoptive immunity and subsequently lead to the development of various diseases [1-6]. Job stress - an important entity of chronic stress, has also been analyzed as a possible cause of numerous disorders/ diseases. Thus, job stress has been assessed with regard to high blood pressure [7,8], coronary heart disease [9-16], various metabolic disorders [16-18], depression [19] and so on. However, published results concerning association between job stress and health-related problems are not consistent. While the majority of reports show association between job stress and the most frequent health-threatening diseases in the modern world, others fail to confirm this association.

One of the leading and the most frequently-used theoretical models in job stress literature is the "job strain model", developed by Karasek and Theorell [20,21]. This model was originally directed at two major risk dimensions of job stress: psychological job demands and job control. Subjects perceiving high job demands along with low job control are classified as "high strain" employees, an exposure category which is expected to be at a higher risk of experiencing health-related problems. Later, "social support" was added to the model as a third dimension. Lack of social support in the workplace is related to the increase of adverse effects of high demands and low job control [10,22].

According to the literature, there is a lack of coherent job stress research in developing countries. Contrary to the previously identified and well-known occupational risks, such as chemical, biological and physical hazards, the nature of job stress and psychosocial working conditions remains largely unknown in these countries [23].
Serbia is a country in transition with a high unemployment rate. According to various commissioned studies carried out in Serbia, more than a half of all workers perceive their job as very stressful, that is, they experience stress daily at work. Unfortunately, no regular job stress monitoring exists in Serbia, and no instruments are used at the national level to enable regular monitoring of job stress in our country.

In the presented study, Karasek's Job Content Questionnaire with regard to education and age was applied to evaluate job stress placed on workers employed by three public organizations in Serbia. Furthermore, the association between job stress and cardiovascular diseases and endocrine/metabolic disorders was assessed.

\section{MATERIAL AND METHODS}

\section{Study population}

The presented study included 411 male workers aged 21 to 66 years (average: 41.99; median: 40) employed by three public organizations where workers with the same education level have similar salaries. Education levels ranged from primary education to $\mathrm{PhD}$ degree. All participants were full-time workers ( $40 \mathrm{~h} /$ week), none were shift workers. Furthermore, the study population was of uniform ethnic origin.

Group $1(\mathrm{~N}=242)$ consisted of airline mechanics, airline electricians, mechanical engineers and other aircraft maintenance workers employed at the military airport. Group $2(\mathrm{~N}=60)$ included electricians, mechanics, workers in a control center placed in the manufacturing hall, technologists and mechanical engineers employed at the powerhouse. Group $3(\mathrm{~N}=109)$ comprised electricians, chemical technicians, mechanical engineers, electrical engineers, chemical engineers and technologists employed at a military technical institute related to the defense industry. Group 3 included the majority of highly-educated workers. Regarding work environment, all participants 
Table 1. Characteristics of the study population

\begin{tabular}{lc}
\hline \multicolumn{1}{c}{ Variables } & Men \\
& $(\mathrm{N}=411)$ \\
\hline Age (years) (\%) & \\
$<35$ & 26 \\
$35-45$ & 38 \\
$>$ 45 & 36 \\
Education (\%) & \\
high & 29 \\
low & 71 \\
Current smoking (\%) & 45 \\
Alcohol consumption (\%) & 70 \\
Overweight (\%) & 51 \\
Clinical characteristics (\%) & \\
cardiovascular disorders & 26 \\
endocrine/metabolic disorders* & 46 \\
obesity & 22 \\
total serum cholesterol-elevated & 32 \\
serum triglyceride-elevated & 22 \\
glucose-elevated & 7 \\
Job stress characteristics (M \pm SD) & $28(15)$ \\
psychological job demands & \\
decision latitude & $31.5 \pm 4.7$ \\
social support & $69.1 \pm 9.9$ \\
Job strain (\%) & $22.4 \pm 4.0$ \\
low strain & \\
active & \\
passive & \\
high strain (isostrain) & \\
\hline & \\
\hline
\end{tabular}

M - mean; SD - standard deviation.

* Metabolic disorders included obesity, elevated level of total serum cholesterol, triglyceride and glucose (each enumerated indicator separately). Some patients had more than one indicator elevated.

were exposed to chemical hazards and adverse effects of noise in their workplace. Given the demands and the nature of the work (such as controlling the working process, performing and monitoring experiments, respecting all protection measures at work) highly educated workers often/always spent their working time in halls, hangars, laboratories or outdoors. Despite different hierarchical positions and working tasks, they spent their working hours in the same conditions as low-educated workers.

More detailed characteristics of the study population are presented in Table 1.

\section{Measurement of stress at work}

Job stress was measured according to Karasek and Theorell's job strain model that operates with three scales: Psychological job demand - PJD (in terms of quantity of work, mental requirements and time constraints), decision latitude - DL (in terms of job-related decisions and the possibility of skills development) and social support in the workplace. The questionnaire was translated into Serbian and its accuracy was confirmed by back translation. From the full recommended Job Content Questionnaire version consisting of 49 items [24], 22 items were selected. PJD scale was based on five items while the DL and social support scales were composed of two subscales. DL was calculated as the sum of skills discretion (six items) and decision authority (three items), while social support (SS) was the sum of coworker support (four items) and supervisor support (four items). Each item had four levels of response from "fully disagree" to "fully agree". The presented study included only the questionnaires with all values in each of the analyzed scales.

The cross-classification of both PJD and DL scales according to their median values in the working population produced a quadrant scheme with the following categories: "Low strain" (low PJD and high DL), "active" (high PJD and high DL), "passive" (low PJD and low DL) and "high strain" (high PJD and low DL). "Isostrain" was referred as a high strain combined with low support (social support score below the median).

\section{Clinical examination}

Clinical examinations took place at the Institute of Occupational Health, MMA and were performed by trained 
nurses and medical doctors specializing in occupational health.

Firstly, blood samples were taken and shipped to the Central Laboratory, MMA for blood cell counts and determination of the serum levels of total cholesterol, triglyceride and glucose. Subsequently, the study participants were subjected to ECG, blood pressure measurement and common examinations by occupational health specialists. Data concerning education, smoking status, alcohol consumption and the presence of chronic diseases was obtained by the use of an interview. If necessary, the patients were examined by other medical specialists. All laboratory and clinical procedures were performed in accordance with national regulations concerning conduction of periodic medical examinations in workers deployed to jobs with greater health risk.

After medical examinations, the patients were asked to complete the questionnaire.

The participants with primary and high school education were considered as "low educated", while education level was considered "high" in the case of the participants with a college or university diploma, MSc or $\mathrm{PhD}$ degree. The participants were divided according to age into three groups: younger than 35 years, 35 to 45 years and older than 45 years. Alcohol consumption was regarded as either periodical, every day up to two drinks or less than 20 alcoholic drinks per week, or often, more than 20 alcoholic drinks per week. Teetotalers and workers who usually do not drink, except for special occasions (with no excessive drinking) were considered as not drinking alcohol. Smokers were defined as those who smoke one or more cigarettes per day. A body mass index, calculated as mass $(\mathrm{kg}) /$ height $(\mathrm{m})^{2}$, between 25 and 29 was considered as overweight, and 30 or higher as obesity.

In the presented study, cardiovascular diseases included hypertension (higher than 130/85 mmHg), myocardial infarction and arrhythmia. Metabolic disorders included obesity, elevated level of total serum cholesterol, triglyceride and glucose (each indicator enumerated separately). Some patients had an abnormal value for only one indicator, but others had abnormal values for two or even three. Endocrine diseases included diabetes mellitus.

\section{Statistical analysis}

The comparison of PJD, DL and SS values between groups was performed using the one-way ANOVA test. Distribution of job stress categories in different education and age groups was analyzed by the use of the $\chi^{2}$ test as well as the relationship between job stress categories and various disorders. The level of statistical significance was set at 0.05 .

Statistical analyses were performed using Statistica 8.0 (Stat Soft. Inc, Tulsa, OK, USA).

\section{RESULTS}

\section{Mean and standard deviations of scales constituting the job strain questionnaire}

No significant statistical difference of mean PJD values was found between the male workers of groups 1,2 and 3. The mean DL values of group 1 and group 2 were similar, while the mean DL of group 3 was significantly higher (one-way ANOVA, $p<0.0001$ ). Furthermore, statistical analysis showed that mean SS values were similar in groups 1 and 3 , while the value of group 2 was significantly lower (one-way ANOVA, $\mathrm{p}<0.0001$ ).

No significant difference was found between highly-educated workers and low-educated workers with regard to mean PJD and SS values. However, highly-educated workers demonstrated significantly higher mean DL values than the low-educated workers (one-way ANOVA, $\mathrm{p}<0.0001)$.

Further comparison between workers from different age groups ( $>45,35-45$ and $<35$ years) showed no significant difference between mean PJD and mean SS values. 
Analysis of mean DL values highlighted a significant difference between all age groups (one-way ANOVA, $\mathrm{p}<0.0001)$ : the highest DL value was observed in the oldest group, while the lowest DL mean was found in the youngest group. The obtained results are summarized in Table 2.

Table 2. Mean values and standard deviations of the Job Content Questionaire Scales in workers from different public organizations, educational and age groups

\begin{tabular}{lccc}
\hline \multirow{2}{*}{ Variables } & \multicolumn{3}{c}{ Job Content Questionaire Scales } \\
\cline { 2 - 4 } Groups & PJD & DL & SS \\
(M \pm SD) & & & \\
group 1 & $31.84 \pm 4.47$ & $66.36 \pm 8.62$ & $22.09 \pm 4.10$ \\
group 2 & $31.90 \pm 3.79$ & $69.43 \pm 10.9$ & $16.37 \pm 6.56$ \\
group 3 & $30.68 \pm 5.54$ & $75.01 \pm 9.49$ & $23.05 \pm 3.90$ \\
p & 0.08 & $<0.0001$ & $<0.0001$ \\
Education & & & \\
(M \pm SD) & & & \\
high & $30.04 \pm 5.48$ & $75.00 \pm 10.86$ & $22.75 \pm 4.65$ \\
low & $31.63 \pm 4.36$ & $66.67 \pm 8.38$ & $22.25 \pm 3.76$ \\
p & 0.51 & $<0.0001$ & 0.26 \\
Age (years) & & & \\
(M \pm SD) & & & \\
$<35$ & $32.20 \pm 4.33$ & $65.04 \pm 9.31$ & $21.95 \pm 4.34$ \\
$35-45$ & $31.28 \pm 5.05$ & $67.95 \pm 8.15$ & $22.58 \pm 3.95$ \\
$>45$ & $31.09 \pm 5.29$ & $73.33 \pm 10.53$ & $22.59 \pm 3.91$ \\
p & 0.18 & $<0.0001$ & 0.38 \\
\hline
\end{tabular}

PJD - psychological job demands; DL - decision latitude; SS - social support.

$\mathrm{p}$ - value according to one-way ANOVA test.

Other abbreviations as in Table 1.

\section{Job stress analyses in different education groups}

The frequency of job stress categories was significantly different between male workers with high and low education ( $\chi^{2}$ test, $\left.\mathrm{df}=3, \mathrm{p}<0.0001\right)$. The majority of highlyeducated workers were exposed to "active" jobs (47\%) and "low strain" jobs (27\%), while only $9 \%$ were exposed to "high strain" jobs. On the contrary, the majority of low educated workers were exposed to "high strain" (35\%) and "passive" $(26 \%)$ jobs, while $16 \%$ of them were exposed to "low strain" jobs. These findings were confirmed by analyses performed within the individual groups 1,2 and 3. The obtained results are summarized in Table 3.

Table 3. Job strain categories between the groups differing in age and education

\begin{tabular}{|c|c|c|c|c|}
\hline \multirow[t]{2}{*}{ Variables } & \multicolumn{4}{|c|}{$\begin{array}{c}\text { Job strain } \\
(\%)\end{array}$} \\
\hline & high strain & active job & passive job & low strain \\
\hline \multicolumn{5}{|l|}{ Education } \\
\hline high & 9 & 47 & 17 & 27 \\
\hline low & 35 & 23 & 26 & 16 \\
\hline \multicolumn{5}{|l|}{$\mathrm{p}<0.0001$} \\
\hline \multicolumn{5}{|l|}{ Age (years) } \\
\hline$<35$ & 40 & 22 & 24 & 14 \\
\hline $35-45$ & 32 & 28 & 26 & 14 \\
\hline$>45$ & 14 & 37 & 20 & 29 \\
\hline $\mathrm{p}<0.0001$ & & & & \\
\hline
\end{tabular}

$\mathrm{p}$ - value according to $\chi^{2}$ test.

\section{Job stress analyses in different age groups}

For male workers, the frequency of job stress categories was significantly different between age groups $\left(\chi^{2}\right.$ test, $\mathrm{df}=6, \mathrm{p}<0.0001)$. The majority of workers older than 45 years were exposed to "active" jobs (37\%) and "low strain" jobs (29\%), while only $14 \%$ were exposed to "high strain" jobs. In the group of workers aged 35 to 45 years, the majority were exposed to "high strain" jobs (32\%), 28\% to "active" and 26\% to "passive" jobs. The majority of workers younger than 35 years were exposed to "high strain" jobs (40\%) and "passive" jobs (24\%), while only $14 \%$ were exposed to "low strain" jobs. However, these findings were not confirmed when individual groups 1, 2 and 3 were analyzed. The obtained results are summarized in Table 3. 


\section{Job stress and clinical characteristics}

In the analyzed population, $26 \%$ of male workers displayed some cardiovascular disorders. However, the frequencies of cardiovascular disorders were not significantly different between workers exposed to different job stress categories ( $\chi^{2}$ test). Furthermore, $46 \%$ of workers had some endocrine or/and metabolic disorders, most of them related to fat metabolism. The frequencies of metabolic disorders were similar between different job stress categories ( $\chi^{2}$ test). No significant differences between job stress groups ( $\chi^{2}$ test) were revealed by separate analyses of blood pressure, overweight, obesity, smoking or alcohol consumption, as well as serum levels of cholesterol, triglyceride and glucose. Despite the absence of statistical significance, it is notable that $34 \%$ of the participants from the "low strain" group were smokers, while $47 \%$ were from the "active" and 49\% were from the "passive" and "high strain" groups. In the "isostrain" group, 56\% of the participants were smokers. The obtained results are not demonstrated in any of the tables.

\section{"Isostrain" analysis}

In the analyzed group, 61 participants characterized their job as "isostrain": a "high strain" job combined with low social support. The analysis of men exposed to "isostrain" jobs showed that $91 \%$ of them were low educated. Furthermore, $17 \%$ of workers were older than 45 years, $46 \%$ of them were 35 to 45 years old, while $37 \%$ were younger than 35 years.

Analysis of clinical characteristics of "isostrain" male workers showed that $20 \%$ of them had cardiovascular disorders and $41 \%$ had endocrine or/and metabolic disorders, most of which were related to fat metabolism. In addition, $56 \%$ of "isostrain" workers were smokers, $75 \%$ consumed alcohol (periodically or often), $51 \%$ were overweight and obesity was observed in $20 \%$ of them. The obtained results are not shown in any of the tables.

\section{DISCUSSION}

The presented study included 411 participants, who completed the Job Content Questionnaire in order to classify their jobs based on the job strain model. In addition, job stress was assessed with regard to education, age and health-related problems.

At first, obtained PJD, DL and SS values were analyzed. Significantly higher DL values were found in highlyeducated and older workers, respectively. DL values were the highest in group 3, where the majority of workers had high education. The possible explanation for this finding is that the participants with high education and/or older workers, with greater work experience, usually hold better positions in the public organizations analyzed in this study. The analysis of PJD values did not show any significant differences between different educational and age groups, respectively.

According to the Job Content Questionnaire, 19\% of men included in the study were exposed to "low strain" jobs, $29 \%$ to "active" jobs, $24 \%$ to "passive" and $28 \%$ to "high strain" jobs (15\% "isostrain"). Similar results have been reported elsewhere. For example, Bacquer et al. analyzed perceived job stress in middle-aged men and women working in 25 large industries or administrations across Belgium. In their study, $26 \%$ of workers were exposed to "low strain" jobs, 30\% to "active" jobs, $27 \%$ to "passive", $17 \%$ to "high strain" and $11 \%$ to "isostrain" jobs [9]. Also, according to Guimont et al., 19\% of male workers characterized their job as "low strain", $28 \%$ as "active", $35 \%$ as "passive" and $18 \%$ as "high strain" job [7]. In the presented study, the frequencies of job stress categories were significantly different between low and highly educated men. The majority of highly-educated men were exposed to an "active" job (high psychological job demands and high decision latitude). The possible explanations for these findings are provided in the paragraph above, where DL values in workers with different levels of education are discussed. 
The analysis of job stress categories in different age groups showed that men older than 45 years most often experienced jobs of high decision latitude ("active" and "low strain"). Men aged 35 to 45 years were most frequently exposed to jobs of high psychological demands ("high strain" and "active"), while the majority of men younger than 35 years were exposed to jobs of low decision latitude ("high strain" and "passive"). As stated above, in public organizations, more experienced workers are usually better positioned and more involved in decision making. The highest psychological demands observed in the middleaged group of workers may be explained by their position at work. Their capabilities and results are most frequently under constant estimation, but their working enthusiasm is lower than it is in younger workers.

The main research objective of this study was to perform an investigation of the relationship between job stress and health-related problems. The overview of published data indicated that majority of studies have analyzed the impact of job stress on the incidence of cardiovascular diseases and associated mortality. Many studies confirmed that job stress increased the risk of cardiovascular diseases [2529]. These studies highlight the adverse effects of low control at work, low social support, high job strain and also, job insecurity and effort-reward imbalance resulting in cardiovascular diseases. In our study, association between exposure to different job stress categories and incidence of cardiovascular diseases was not observed. The lack of any convincing association between exposure to job stress and incidence of cardiovascular diseases has previously been reported elsewhere [9,30,31]. For example, Eaker et al. report the absence of association between high job strain and coronary heart disease in either men or women. Contrary to the expectations, they found that women with "active" jobs were at higher risk of coronary heart disease than women exposed to "high strain" jobs [31].

Taking into account metabolic/endocrine disorders, data from the literature indicates that job stress may be an important risk factor for metabolic syndrome [32], particularly in shift workers $[16,33,34]$. However, our study did not confirm the presence of any association between incidence of metabolic/endocrine diseases and exposure to different categories of job stress. No statistically significant differences between job stress groups were found by independent analyses with regard to blood pressure, overweight, obesity, smoking, alcohol consumption, or serum levels of cholesterol, triglyceride or glucose. Our results, obtained in a small group of women, showed that women experiencing "low strain" and "active" jobs more often had normal body weight (data not presented). The possible explanation for this finding is that stress may contribute to changes in dietary behaviors in women exposed to "passive" and "high strain" jobs. The association between exposure to job stress and obesity was documented by Brunner et al. In their study, employees experiencing chronic job stress had approximately $50 \%$ higher chances of obesity compared with those without job stress, after taking into account socio-economic and behavioral parameters [11]. Association between job stress (or lower job control, higher job strain and higher effort-reward imbalance) and weight gain has also been reported by Block et al. and Kouvonen et al. [35,36].

In the presented study, 61/411 participants (15\%) were exposed to "high strain" jobs (high job demands and low job control) associated with lack of social support ("isostrain" group). According to the literature, this group is expected to be at higher risk of experiencing health-related problems. In our study, the "isostrain" group included mainly low-educated men (91\%) and men younger than 45 years $(83 \%)$. We can assume that the high proportions of smokers (34/61), workers who consume alcohol (46/61) and workers with weight problems (31/61 overweight and 12/61 obese) found in this group demonstrate the adverse effects of high job strain combined with low social support. In conclusion, the presented study indicates that loweducated men as well as men younger than 45 years are 
more often exposed to unfavorable job categories ("high strain" and "passive" jobs). However, no clear association between job stress and cardiovascular diseases, or metabolic/endocrine diseases has been found. To the best of our knowledge, this is the first study that has assessed job stress in workers employed by public organizations in our country. The limitation of this study is the small number of participants. However, the study population is very homogenous - all the participants are of the same ethnicity, work in public organizations, are exposed to chemical hazards and adverse effects of noise in their workplace and they attend annual medical examinations in one medical institution.

Despite the absence of a clear association between job stress and health-related problems, we recommend prevention of work stress, particularly in young, low-educated workers, where unfavorable job stress categories were most frequently found.

\section{ACKNOWLEDGEMENTS}

The authors thank all of the participants for taking part in this study.

\section{REFERENCES}

1. Kiecolt-Glaser JK, Preacher KJ, MacCallan RC, Atkinson C, Malarkay WB, Glaser R. Chronic stress and age-related increases in the proinflammatory cytokine IL-6. Proc Natl Acad Sci USA 2003;100(15):9090-5.

2. Bierhaus A, Wolf J, Andrassy M, Rohleder N, Humpert PM, Petrov D, et al. A mechanism converting psychosocial stress into mononuclear cell activation. Proc Natl Acad Sci USA 2003;100(4):1920-5.

3. Peters ML, Godaert GLR, Ballieux RE, Brosschot JF, Sweep FCGJ, Swinkels LMJW, et al. Immune responses to experimental stress: Effects of mental effort and uncontrollability. Psychosom Med 1999;61(4):513-24.
4. Chen E, Fisher EB, Bacharier LB, Strunk RC. Socioeconomic status, stress and immune markers in adolescents with asthma. Psychosom Med 2003;65(6):984-92.

5. Glaser R, Sheridan J, Malarkey WB, MacCallum RC, Kiecolt-Glaser JK. Chronic stress modulates the immune response to a pneumococcal pneumonia vaccine. Psychosom Med 2000;62(6):804-7.

6. Nelson EL, Wenzel LB, Osann K, Dogan-Ates A, Chantana N, Reina-Patton A, et al. Stress, immunity, and cervical cancer: Biobehavioral outcomes of a randomized clinical trial. Clin Cancer Res 2008;14(7):2111-8.

7. Guimont C, Brisson C, Dagenais GR, Milot A, Vézina M, Mâsse B, et al. Effects of job strain on blood pressure: A prospective study of male and female white-collar workers. Am J Public Health 2006;96(8):1436-43.

8. Brown DE, James GD, Mills PS. Occupational differences in job strain and physiological stress: Female nurses and school teachers in Hawaii. Psychosom Med 2006;68(4):524-30.

9. De Bacquer D, Pelfrene E, Clays E, Mak R, Moreau M, de Smet P, et al. Perceived job stress and incidence of coronary events: 3-year follow-up of the one Belgian job stress project cohort. Am J Epidemiol 2005;161(5):434-41.

10. Johnson JV, Hall EM. Job strain, work place social support, and cardiovascular disease: A cross-sectional study of a random sample of the Swedish working population. Am J Public Health 1988;78(10):1336-42.

11. Bugajska J, Widerszal-Bazyl M, Radkiewicz P, Pasierski T, Szulczyk GA, Zabek J, et al. Job strain and early atherosclerotic changes in healthy employees. Int Arch Occup Environ Health 2008;81(8):1037-43.

12. Bugajska J, Michalak M, Jedryka-Goral A, Sagan A, Konarska M. Coronary heart disease risk factors and cardiovascular risk in blue- and white-collar workers. Int J Occup Saf Ergon (JOSE) 2009;15(1):35-43.

13. Netterstorm B, Kristensen TS, Jensen G, Schnor P. Is the demand-control model still a useful tool to assess workrelated psychosocial risk for ischemic heart disease? Results 
from 14 year follow up in the Copenhagen city heart study. Int J Occup Med Environ Health 2010;23(3):217-24.

14. Bortkiewicz A, Gadzicka E, Siedlecka J, Szyjkowska A, Viebig P, Wranicz JK, et al. Work-related risk factors of myocardial infarction. Int J Occup Med Environ Health 2010;23(3):255-66.

15. Siegrist J. Effort-reward imbalance at work and cardiovascular diseases. Int J Occup Med Environ Health 2010;23(3):279-85.

16. Szosland D. Shift work and metabolic syndrome, diabetes mellitus and ischaemic heart disease. Int J Occup Med Environ Health 2010;23(3):287-91.

17. Brunner EJ, Chandola T, Marmot MG. Prospective effect of job strain on general and central obesity in the Whitehall II study. Am J Epidemiol 2007;165(7):828-37.

18. Vitaliano PP, Scanlan JM, Zhang J, Savage MV, Hirsch IB, Siegler IC. A path model of chronic stress, the metabolic syndrome, and coronary heart disease. Psychosom Med 2002;64(3):418-35.

19. Robertson Blackmore E, Stansfeld SA, Weller I, Munce S, Zagorski BM, Stewart DE. Major depressive episodes and work stress: results from a national population survey. Am J Public Health 2007;97(11):2088-93.

20. Karasek RA, Theörell T. Healthy work-stress, productivity, and the reconstruction of working life. New York: Basic Books; 1990. p. 89-103.

21. Karasek RA. Job demands, job decision latitude, and mental strain: Implications for job redesign. Admin Sci Q 1979;24:285-308.

22. Collins S. Statutory social workers: stress, job satisfaction, coping, social support and individual differences. Br J Soc Work 2008;38:1173-93.

23. Kortum E, Leka S, Cox T. Psychosocial risk and workrelated stress in developing countries: health impact, priorities, barriers and solutions. Int J Occup Med Environ Health 2010;23(3):225-38.

24. Karasek RA. Job content questionnaire and user's guide. Lowell, MA: University of Massachusetts, Department of Work Environment; 1985.
25. Kivimäki M, Leino-Arjas P, Luukkonen R, Riihimäki H, Vahtera J, Kirjonen J. Work stress and risk of cardiovascular mortality: prospective cohort study of industrial employees. Br Med J 2002;325(7369):857-63.

26. Chandola T, Britton A, Brunner E, Hemingway H, Malik M, Kumari M, et al. Work stress and coronary heart disease: what are the mechanisms? Eur Heart J 2008;29(5):640-8.

27. Everson SA, Lynch JW, Chesney MA, Kaplan GA, Goldberg DE, Shade SB, et al.Interaction of workplace demands and cardiovascular reactivity in progression of carotid atherosclerosis: population based study. Br Med J 1997;314(7080):553-8.

28. Rauchenzauner M, Ernst F, Hintringer F, Ulmer H, Ebenbichler C, Kasseroler MT, et al. Arrhythmias and increased neuro-endocrine stress response during physicians' night shifts: a randomized cross-over trial. Eur Heart J 2009;30(21): 2606-13.

29. Kopp M, Skrabski Á, Szántó Z, Siegrist J. Psychosocial determinants of premature cardiovascular mortality differences within Hungary. J Epidemiol Community Health 2006;60(9):782-8.

30. Rozanski A, Gransar H, Kubzansky LD, Wong N, Shaw L, Miranda-Peats R, et al. Do psychological risk factors predict the presence of coronary atherosclerosis? Psychosom Med 2011;73(1):7-15.

31. Eaker ED, Sullivan LM, Kelly-Hayes M, D'Agostino RB, Benjamin EJ. Does job strain increase the risk for coronary heart disease or death in men and women? Am J Epidemiol 2004;159(10):950-8.

32. Chandola T, Brunner E, Marmot M. Chronic stress at work and the metabolic syndrome: prospective study. $\mathrm{Br}$ Med J 2006;332(7540):521-5.

33. Karlsson B, Knutsson A, Lindahl B. Is there an association between shift work and having a metabolic syndrome? Results from a population based study of 27485 people. Occup Environ Med 2001;58(11):747-52.

34. Pietroiusti A, Neri A, Somma G, Coppeta L, Iavicoli I, Bergmaschi I, et al. Incidence of metabolic syndrome among nightshift healthcare workers. Occup Environ Med 2010;67(1): $54-7$. 
35. Block JP, He Y, Zaslavsky AM, Ding L, Ayanian JZ. Psychosocial stress and change in weight among US adults. Am J Epidemiol 2009;170(2):181-92.
36. Kouvonen A, Kivimäki M, Cox SJ, Cox T, Vahtera J. Relationship between workstress and body mass index among 45,810 female and male employees. Psychosom Med 2005;67(4):577-83.

This work is available in Open Access model and licensed under a Creative Commons Attribution-NonCommercial 3.0 Poland License - http://creativecommons.org/ licenses/by-nc/3.0/pl/deed.en. 